Folia Histórica del Nordeste, $\mathbf{N}^{\circ} 19$ (Resistencia, 2011) IIGHI, IH - CONICET, UNNE

\title{
LA INDUSTRIA MADERERA EN LA PROVINCIA DE CHACO COMO ESTÍMULO AL DESARROLLO LOCAL: POSIBILIDADES Y DIFICULTADES
}

\author{
The Timber Industry in the Province of Chaco as a Stimulus to Local Development: \\ Opportunities and Challenges
}

Eduardo Muscar Benasayag, Elena Alfonso y Daniela Torrente

\begin{abstract}
Resumen
El presente trabajo aborda una problemática específica de un sector industrial de la provincia del Chaco profundizando en el tema de la explotación forestal en la Microrregión Centro Chaqueña, en la actualidad, la más importante en generación de empleo industrial, en las ciudades localizadas en este espacio. A pesar de ello, las condiciones en que se desarrollan las industrias no permiten al sector crecer económicamente: miniempresariado, baja calidad de las instalaciones, deficiente organización del proceso productivo, instalaciones con baja tecnología, precarias condiciones de trabajo, bajo grado de aprovechamiento del algarrobo, especulación de los intermediario, entre otras. Además, la tala indiscriminada del algarrobo por la falta de una política de manejo forestal, atenta contra su preservación y amenaza su existencia aún siendo la base que sustenta la producción. Se analizan, además, las posibilidades de crear estrategias para el desarrollo local observando las fortalezas, debilidades, dificultades, el cumplimiento de la escasa legislación existente y la falta de observancia en la reglas preestablecidas. El aporte, resultado de un trabajo de investigación mayor, conduce a la reflexión sobre el uso indiscriminado de los recursos forestales así como a remarcar las posibilidades de revertir la situación actual signada por graves problemas económicos, sociales y ambientales para permitir un desarrollo local sostenible y sustentable.
\end{abstract}

$<$ Industria maderera $><$ Pequeñas y medianas industrias $><$ PyMI $><$ Desarrollo local $><$ Chaco $>$

\begin{abstract}
This paper addresses specific problems of the industrial sector in the Chaco province deeper into the issue of logging in the Microrregión Centro Chaqueña. This region is currently the most important in generating employment, in cities located in this space. Nevertheless, it is not allowed to develop economic growth due to conditions such as: business smallholding, low quality of facilities, poor organization of the production process, low-tech facilities, poor working conditions, low degree of utilization of the carob tree, speculation intermediaries. Moreover, the indiscriminate felling of carob by the lack of forest management
\end{abstract}


policy violates their preservation and threatens their existence which still remains the base that supports production. This contribution is the result of an extensive research focused on the indiscriminate use of the forest resources, and highlights the possibility of reversing the current situation with serious economic, social and environmental benefits to enable sustainable local development.

$<$ Wood industry $><$ PyMI $><$ Local development $><$ Chaco $>$

\section{Introducción}

El presente trabajo tiene por objetivo principal brindar conocimiento sobre un sector concreto de la economía chaqueña, la industria forestal, principalmente la rama de fabricación de muebles y aberturas, a la vez que desde un punto de vista científico a nivel universitario-, alentar la búsqueda de herramientas que permitan su subsistencia y desarrollo por tratarse de uno de los pilares que sostiene la economía provincial y que en la actualidad se enfrenta a serios problemas estructurales. Por otra parte, los resultados que aquí se presentan son parte de un proyecto más amplio desarrollado en la Facultad de Ciencias Económicas de la Universidad Nacional del Nordeste y que plantea la idea de alcanzar estrategias para el desarrollo económico provincial.

"Satisfacer las necesidades de las generaciones presentes sin comprometer las posibilidades de las del futuro para atender sus propias necesidades" (Brundtland, 1987). Esta es la definición actualmente aceptada en el ámbito académico acerca del desarrollo e involucra en la concepción del fenómeno la inclusión de tres dimensiones o pilares sobre los que se sostiene: viabilidad, distribución equitativa de los resultados y que el mismo sea soportable desde el punto de vista ambiental y social.

Para Mladinic (Mladinic, 2002) el desarrollo sustentable se define como una meta final que intentamos alcanzar, lo que significa que es un estado que no existe aún. Por lo tanto nuestras actuales prácticas de desarrollo deben ser corregidas. Requeriremos de un desarrollo que sea ambientalmente adecuado, socialmente responsable y económicamente factible.

Por otra parte, el desarrollo local está contemplado en los Ocho Objetivos del Milenio, concretamente el siete que contempla "garantizar el sustento del medio ambiente" incorporando los principios del desarrollo sostenible en las políticas y programas nacionales y reducir la pérdida de los recursos del medio ambiente y tratar de ralentizar notablemente la reducción de la diversidad biológica hacia $2010 .{ }^{1} \mathrm{La}$ mayor parte de estos objetivos deberían alcanzar las metas más relevantes en 2015. Dada la crisis en que se hallan involucrados los países más desarrollados resulta difícil vislumbrar cambios notables, sobre todo en los aspectos relacionados con el desarrollo local.

Nos parece apropiado resaltar que las características propias de lo local en la evaluación e implementación de alternativas de actuación son indispensables en el

${ }^{\overline{1}}$ Cumbre del Milenio y Declaraciones del Milenio ratificada por 189 países en Nueva York (IX-2000) 
estudio de la posibilidad de corrección de efectos no deseados de prácticas que atentan contra la sostenibilidad de modelos productivos. Esto implica reconocer que desde el interior de la realidad se interpela de manera distinta las necesidades de la misma y así se pueden generar instrumentos capaces de satisfacer demandas más inmediatas de políticas, planes, gestión de riesgo y medición productiva.

Esto implica el replanteo de lo que hoy se denomina una estrategia de desarrollo económico local que apunte al análisis de las características estructurales que condicionan las economías poco desarrolladas, tales como: poco sentido de la territorialidad, falta de alianzas con los actores involucrados y de asociativismo, capital social insuficiente, falta de sostenibilidad ambiental, en un marco de creciente competitividad y globalización económica.

Desde esta perspectiva, "El desarrollo local aparece como una nueva forma de mirar y de actuar desde el territorio en este nuevo contexto de globalización. El desafío para las sociedades locales está planteado en términos de insertarse en forma competitiva en lo global, capitalizando al máximo sus capacidades endógenas, a través de las estrategias individuales pero articuladas de los diferentes actores en juego."(Elizalde Hevia, 2003). Pensar, entonces, en instrumentar una estrategia de desarrollo económico local convoca a diseñar un proceso de transformación de la economía y de la sociedad de un territorio que tienda a superar dificultades y exigencias de adaptación y cambio propias del actual contexto en el que las características esenciales son la creciente competitividad y globalización económica, así como también una mayor valorización de la sostenibilidad ambiental, con el fin de mejorar las condiciones de vida de la población de ese territorio. Pero esta estrategia implica, además, repensar ese proceso valorando el aporte y la actuación protagónica de los actores involucrados con ese territorio: productores, gobiernos municipales y provinciales, asociaciones y entidades empresariales de la región, entre otros.
"Para ello se requiere una actuación decidida y concertada entre los diferentes actores locales, públicos y privados, a fin de crear un entorno territorial que fomente las actividades productivas en general y en especial las que corresponden a las microempresas y las pequeñas y medianas empresas, para utilizar en forma eficiente y sostenible los recursos endógenos y aprovechar las oportunidades de dinamismo exógeno o el dinamismo de las actividades empresariales presentes en el territorio". (Alburquerque, et al; 2001).

El desarrollo no necesariamente se basa en factores endógenos, puede también depender del aprovechamiento de oportunidades que brinda el contexto. Sí, existen factores exógenos que pueden posibilitar el desarrollo de una determinada región, y no ponemos en duda que estos factores siempre están presentes. Su aprovechamiento consiste en crear una estrategia que permita endogeneizar los efectos favorables de esa oportunidad generada por el contexto, es decir, transformar la misma en una fortaleza 
para la región; pero siempre teniendo en consideración las características locales, no con paquetes de recomendaciones. Esta propuesta parte de la base de que lo local imprime un sello propio a las medidas a implementar.

"La política de desarrollo económico local insiste en que
hay que identificar a las microempresas y pequeñas y
medianas empresas no solo por medio de catastros o censos
de empresas, sino en sus eslabonamientos productivos y en
su correspondiente territorio, ya que no compiten aisladas
sino dentro de esos encadenamientos y de su localización o
entorno territorial. Sólo incorporando estos aspectos pueden
visualizarse los problemas concretos relativos a la innovación
tecnológica y empresarial, y definirse la calificación de
recursos humanos que es necesaria para adecuar la oferta de
instrumentos de fomento productivo e innovación existentes,
así como los recursos e instrumentos de capacitación, a la
demanda de innovación subyacente en los diferentes sistemas
productivos locales." (Alburquerque, et al; 2001).

Partimos de la premisa de que el conocimiento acabado de las particularidades que afectan a cada sector de actividad permite construir territorialmente los mercados estratégicos de factores y servicios de apoyo a la producción de las pequeñas y medianas empresas de una región. La visión del desarrollo económico local da prioridad a las micro y medianas empresas debido a la alta proporción que representan en regiones poco desarrolladas y su importancia para el empleo y la generación de ingresos; esto permite elaborar una política de innovación productiva y empresarial coherente con los objetivos de una justicia distributiva y social y no desde una perspectiva exclusivamente asistencialista. El problema con el que nos encontramos es que estas micro y medianas empresas no tienen una visión clara de los datos de orden estratégico, ni de estrategias basadas en la utilización de nuevas tecnologías, introducción de exigencias de calidad, diferenciación productiva y establecimiento de redes de cooperación empresarial para enfrentar en mejores condiciones las mayores exigencias de competitividad de los mercados que son las condiciones básicas para alcanzar una estrategia de desarrollo sostenible y sustentable, y cuando las poseen, no siempre tienen acceso a posibilidades de financiamiento que les permita concretar las mismas.

En la provincia del Chaco, la industria maderera se trata asimismo del sector secundario más numeroso pero al mismo tiempo uno de los más frágiles y vulnerables del tejido empresarial, que por si solo, no está preparado para enfrentar las dificultades de la actual fase de cambio estructural y las mayores exigencias de competitividad de los mercados y, por el momento en el nordeste argentino no hay elementos que permitan inferir que se está dando un proceso de construcción territorial en cuanto a la oferta de servicios para la producción: ventajas del transporte ferroviario de carga y pasajeros, infraestructuras que permitan la llegada de gas natural, entre otras. 
Guiados por estos avances en cuanto a la concepción del desarrollo fue nuestra intención abordar la problemática específica de un sector industrial de la provincia del Chaco, profundizando en el tema de la explotación e industria forestal, principalmente la fabricación de muebles y aberturas dentro de la región. En la actualidad es una rama muy importante en la generación de empleo privado en el Chaco, y como tal, su estudio reviste una importancia significativa. Según datos provenientes de investigaciones realizadas con anterioridad por otras Universidades, como la de Bolonia, citada en la publicación: "La Nueva Geografía Industrial Argentina: distribución territorial y especialización sectorial de las pequeñas y medianas industrias en el año 2000" donde se destaca que éste es el sector más importante en las ciudades de Machagai, Presidencia de la Plaza, Villa Berthet y Quitilipi representando en algunas de ellas más del 90\% del empleo PyMI, situación que en la investigación desarrollada ha sido confirmada por los datos de locales con actividad industrial y de empleo, provenientes del Censo Nacional Económico de 2005.

La actividad forestal y sus derivados son muy importantes para la región pero ambas están minadas de problemas y dificultades; por tal motivo conocerlos y analizar cuáles son estas dificultades y sus posibilidades de subsistencia de las actividades derivadas es de vital importancia. En el marco de los estudios realizados dentro del Programa CERPYME ${ }^{2}$ Argentina se realizó un diagnóstico del sector maderero en el Chaco del cual se desprende que el mismo enfrenta problemas tales como la precariedad de las miniempresas, baja calidad de las instalaciones, deficiente organización del proceso de fabricación, empleo de maquinaria muy elemental, frágiles condiciones de seguridad e higiene laboral, escaso grado de aprovechamiento integral del rollo de algarrobo para los fines de la producción industrial, -solamente el 20\%-, condiciones de comercialización dependientes de las posibilidades ofrecidas por los intermediarios financieros (usureros) en el momento del abastecimiento de la materia prima y de la venta del producto final, y de los acopiadores (compradores - intermediarios) de forma que el industrial es un "operador ciego" que carece de información sobre el real funcionamiento del mercado de sus productos.

La supresión de estos cuellos de botella, claramente financieros/institucionales, es una condición necesaria e inaplazable para la plena incorporación del sector transformador al mercado de sus productos. Todos estos temas han sido profundizados en nuestro trabajo a través de la realización de entrevistas focalizadas a diferentes

\footnotetext{
${ }^{2}$ El Programa CERPYME ARGENTINA fue el resultado de un Convenio de Cooperación y Financiación entre la Unión Europea y el gobierno de la República Argentina (la Secretaría de la Pequeña y Mediana del Ministerio de Economía) y apuntó a mejorar la competitividad de las PyME en la búsqueda de su internacionalización y a impulsar el desarrollo de las economías regionales, capitalizando la experiencia europea en beneficio de nuestras empresas e instituciones. Sus objetivos específicos eran:

- fortalecer las estructuras de apoyo a las PyME en distintas provincias de Argentina, entre ellas Chaco,

- organizar un sistema nacional de capacitación y asistencia técnica a todos los niveles institucionales,

- fomentar las alianzas estratégicas entre empresas y dar apoyo a la búsqueda de socios internacionales,

- fortalecer los sistemas de información y monitoreo para las PyME,

- búsqueda y apoyo de sistemas alternativos de financiación a las PyME.
} 
actores que participan de la cadena foresto industrial.

\section{Desarrollo}

\subsection{Una explicación incipiente al origen de los problemas}

¿Por qué se da esta actividad en estas condiciones en el ámbito provincial? Una explicación a la que arribamos luego de analizar las entrevistas realizadas es que la situación actual se inicia como una alternativa, prácticamente improvisada, por la falta de oferta de empleo y que caracteriza a la región durante los últimos 30 años. La industria maderera surge como una forma de paliar las sucesivas y recurrentes crisis que afectaron el nivel de actividad económica de la provincia. También como resultado de malas campañas algodoneras, siendo el cultivo del algodón y su valor agregado el sustento principal en los años anteriores a la década de los años 90 y los ingresos originados en el sector privado. Esta crisis estructural que atravesó el sector algodonero dada por cambios climáticos que se tradujeron en condiciones meteorológicas desfavorables, la competencia de nuevos productos sustitutos del algodón en la producción de bienes, el desarrollo de nuevos cultivos que compiten por el uso de la tierra con el algodón y la política activa de subsidios a la producción primaria que han aplicado los países desarrollados, entre otros factores, se trasladó a su vez a varios sectores de la sociedad chaqueña ya que la misma tenía su sistema productivo estructurado en torno a dos grandes actividades: cultivo e industrialización del algodón y la forestal taninera. Con respecto a esta última, de las 15 fábricas que procesaban rollizos para la obtención de extracto tánico en la provincia en la década del '70 quedaban en 1990 solo tres y en la actualidad subsisten dos. El productor había adquirido la cultura del algodón por tradición y sabía perfectamente cómo desenvolverse en el tiempo y en el espacio. Cuando esa estructura se desplomó, gran parte del sistema productivo del Chaco se extinguió.

Hoy, en la provincia, la foresto industria presenta una fuerte concentración vertical ya que se da desde la obtención de materia prima y el aserrado de la misma hasta la producción de muebles y aberturas. Estos emprendimientos, surgen como una alternativa a la falta de empleo, sin un conocimiento acabado del proceso productivo, siendo ésta una de las razones que impidieron hacer más eficiente el uso del recurso.

Transcurridos varios años, estas cuestiones se han transformado en un factor decisivo que hace peligrar la continuidad y sustentabilidad de los mismos en el tiempo, ya que el recurso forestal comienza a ser cada vez más escaso por su uso irracional, afirmación que se sustenta en que si se analiza de dónde proviene la ventaja competitiva de estos productos, se arriba a la conclusión de que mucho tiene que ver con las bondades del algarrobo y la falta de este tipo de madera en otras regiones o países, que permite que sus derivados o subproductos no compitan con otros que se fabrican en el ámbito nacional e internacional. 


\subsection{Caracterización general de la actividad.}

Distribución territorial. La actividad industrial maderera se desarrolla en diferentes localidades de la provincia del Chaco pero fundamentalmente en la Micro Región Centro (número 2 en el mapa adjunto) integrada por los departamentos: Quiltilipi, 25 de Mayo y San Lorenzo cuyas ciudades cabeceras son Machagai, Presidente La Plaza y Villa Berthet respectivamente. La actividad también es relevante en las localidades de Resistencia, Villa Ángela y San Bernardo y en los departamentos de General Güemes y Maipú cuyas ciudades cabeceras son Juan José Castelli y Tres Isletas.

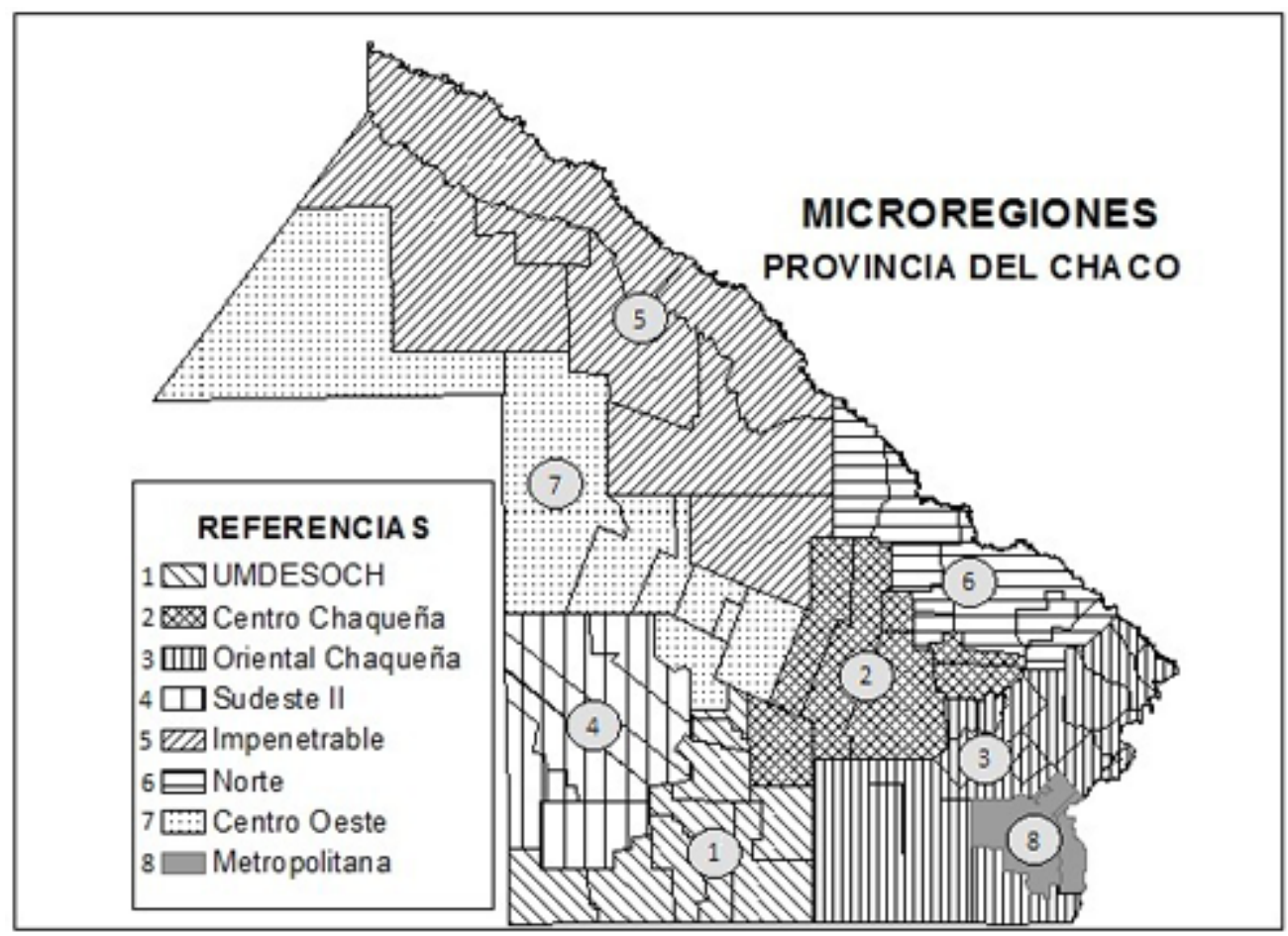

Las ramas de particular interés para este estudio, son la 20100: Aserrado y cepillado de madera, 20220: Fabricación de partes y piezas de carpintería para edificios y construcciones y 36101: Fabricación de muebles y partes de muebles, principalmente de madera, relacionadas con la industrialización de la madera.

Resulta importante tener en cuenta la concentración geográfica de las ramas relacionadas con la utilización de madera como materia prima. A escala provincial se hallan concentradas espacialmente de la siguiente manera: rama 20100: Aserrado y cepillado de madera en los municipios de Tres Isletas, Juan José Castelli, Villa

\footnotetext{
${ }^{3}$ Según CLANAE 97. Clasificador Nacional de Actividades Económicas, utilizado por INDEC y los organismos provinciales para agrupar la información económica sectorialmente.
} 
Ángela y General San Martín; rama que representa el abastecimiento de materia prima en torno a las localidades en las que todavía hay algarrobo y otras maderas para transformarlas en madera aserrada; la rama 20220: Fabricación de partes y piezas de carpintería para edificios, construcciones y producción de aberturas, en el municipio de Quitilipi, el cual concentra prácticamente el 50\% de los locales, y el resto se distribuye en Resistencia, Presidencia Roque Sáenz Peña y Presidencia de la Plaza y la 36101: Fabricación de muebles y partes de muebles principalmente de madera, se localiza en su mayor parte en Machagai y Presidencia de la Plaza. Este patrón de especialización que tienen algunas localidades como ser Quitilipi, Machagai y Presidencia de la Plaza es importante debido a que significa producciones orientadas a mercados diferentes, con distinto valor agregado, precios y tipos de madera utilizadas, y es importante tenerlo en consideración ante la definición de políticas que hacen al uso racional de los recursos forestales y para un eficiente desarrollo local.

\section{Importancia de las ramas dentro del total de locales con actividad industrial y dentro del empleo industrial}

En la Provincia de Chaco, según el Censo Nacional Económico 20044 (CNE 04), existían 2399 locales con actividad industrial de los cuales el 85\% ocupaba menos de 6 personas, $11 \%$ de 1 a 5 ocupados y solo 4 más de 200, incluidas en esta última cifra dos tanineras localizadas en La Escondida y Puerto Tirol, una planta textil, también en Puerto Tirol y un establecimiento que elabora jugos y gaseosas en Barranqueras. Solo 335 locales empleaban a 6 o más empleados, 4 empleaban a más de 200 operarios. En el detalle de porcentaje de locales por rama de actividad se podrá observar, a su vez, cuales son las ramas predominantes y se mencionarán algunos aspectos vinculados con estos datos. De acuerdo a la información censal, si lo que se toma en cuenta como elemento de análisis es la cantidad de locales, la 36101 se ubica en segundo orden de importancia, después de la fabricación de productos de panadería. La 20220 en $5^{\circ}$ orden y la 20100 en $7^{\circ}$ lugar de un total de 104 sectores con actividad industrial relevados.

\section{Total de locales industriales. Año 2004}

\begin{tabular}{|c|c|c|c|c|c|}
\hline Provincia / Departamento & $\begin{array}{c}\text { Total de } \\
\text { locales }\end{array}$ & $\begin{array}{c}\text { menos } \\
\text { de 6 } \\
\text { ocupados }\end{array}$ & $\begin{array}{c}\text { entre 6 } \\
\text { y 200 } \\
\text { ocupados }\end{array}$ & $\begin{array}{c}\text { más de } \\
\mathbf{2 0 0}\end{array}$ & $\begin{array}{c}\text { sin dato de } \\
\text { personal }\end{array}$ \\
\hline Provincia de Chaco & 2399 & 2053 & 335 & 4 & 6 \\
\hline
\end{tabular}

Fuente. DPE en base a información del Censo Nacional Económico 2004-2005.

\footnotetext{
${ }^{4}$ En la Dirección Provincial de Estadística de la Provincia de Chaco se ha realizado una recodificación de la base de locales censados a efectos de corregir errores de codificación y poder asignar mejor las actividades productivas, esta base recodificada es la tomada en cuenta en el análisis, los datos de empleo y cantidad de locales están basados en las guías de empadronamiento..
} 
La afirmación de que la mayoría de las industrias emplean menos de 6 trabajadores es una información distorsionada. El dato no es real ya que en las carpinterías trabajan familias completas, padres, hermanos, hijos. También trabajan mujeres de la familia en la parte administrativa pero debido a la informalidad con que se manejan estos establecimientos estas personas no están declaradas en el censo. Esta característica se da con más fuerza en esta actividad que en el resto de las censadas.

\section{Empleo industrial generado por las ramas bajo estudio}

A continuación se muestran datos del empleo generado por la industria en la provincia al igual que en las ramas relacionadas con la madera. Las ramas analizadas tienen una participación dentro del empleo industrial total en la provincia de más del $20 \%$ y si a estos datos sumamos los puestos de trabajo generados en las dos plantas productoras de tanino este porcentaje se eleva a más del $25 \%$.

Industria manufacturera. Puestos generados. Ramas 20100, 20220, 36101 y 24112. Chaco. Año 2004

\begin{tabular}{|l|c|c|}
\hline $\begin{array}{l}\text { Cantidad total de puestos de trabajo generados por } \\
\text { la industria }\end{array}$ & $\mathbf{1 1 . 0 6 0}$ & $\mathbf{1 0 0 , 0 0}$ \\
\hline Rama 20100 (Aserrado y cepillado de madera) & 625 & 5,65 \\
\hline $\begin{array}{l}\text { Rama 20220 (Fabricación de partes y piezas de } \\
\text { carpintería para edificios y construcciones }\end{array}$ & 500 & 4,52 \\
\hline $\begin{array}{l}\text { Rama 36101 (Fabricación de muebles y partes de } \\
\text { muebles, principalmente de madera) }\end{array}$ & 1.186 & 10,72 \\
\hline subtotal & $\mathbf{2 . 3 1 1}$ & $\mathbf{2 0 , 9 0}$ \\
\hline Rama24112 (Producción de tanino) & 567 & 5,13 \\
\hline Total puestos generados por la industria forestal. & 2.878 & 26,02 \\
\hline
\end{tabular}

Fuente. Elaboración propia-. Datos del Censo Nacional Económico 2004-2005

Esta parte del trabajo se basa en conclusiones elaboradas a través de series de entrevistas a informantes clave y visitas a aserraderos y carpinterías de las localidades de Quitilipi y Machagai, con el objetivo de obtener información cualitativa que nos permita caracterizar y comprender el sistema en que está inmersa la problemática de la industria forestal en la Provincia del Chaco e identificar móviles que condicionan cualquier medida tendiente a la preservación de la misma. A esta interpretación del problema forestal se adiciona el valioso aporte del Ingeniero Forestal Martín Romano, Responsable Técnico del Proyecto de Investigación Aplicada de Recursos Forestales Nativos (PIARFON), Chaco Subhúmedo (UNNE/UNAF(BIRF) de reconocida 
trayectoria en la provincia. En forma conjunta con el Ingeniero Romano se realizaron entrevistas y trabajos en común.

\section{Realidad actual de las PyMES relacionadas con la industrialización de la madera}

\subsection{Etapas del proceso productivo}

Abastecimiento: La mayor parte de la madera se extrae del monte nativo, y en esta etapa se desarrollan actividades de limpieza de caminos y apertura de picadas, talado del árbol, etc. Como la mayor parte de la extracción procede del monte nativo, la deforestación ha hecho cada vez más complicada esta actividad ya que se tiende a incrementar la explotación en zonas más alejadas e inhóspitas de la provincia y tiene un doble efecto: encarece cada vez más el costo de trasladar el rollo hasta la carpintería y cuando llueve intensamente, las carpinterías quedan desabastecidas interrumpiendo su producción y para evitar esto se ven obligadas a mantener importantes reservas de madera. En esta etapa del proceso se utilizan máquinas de escaso contenido tecnológico.

Industrialización de la madera: comprende el aserrado, confección de muebles, aberturas, pisos y techos e insumos para el campo. Por lo general, la mayor parte de los locales produce de "todo un poco" lo cual impide la especialización y estandarización de productos. Esta etapa genera una gran cantidad de desechos que en un porcentaje importante se utilizan como leña y aserrín. El estado rudimentario de la mayor parte de los locales productivos genera malas condiciones de trabajo para el operario y contaminación del aire en zonas aledañas a zonas urbanas. Algunas están ubicadas dentro del casco urbano. Con referencia a este aspecto no existen controles y son escasos los establecimientos que se han ocupado de tratar el problema de la contaminación en el lugar del trabajo.

Carpintería: luego de aserrada y secada la madera es destinada a la elaboración del producto final y en esta etapa se realizan las siguientes actividades: despuntado, que consiste en el emparejamiento de la madera y el corte de acuerdo al producto concreto al que va destinada, cepillado, torneado, barreno y espigadomiento, armado, lustrado, encerado, etc. Para realizar estas actividades se utilizan máquinas que difieren en precisión y calidad de acuerdo la importancia y tamaño de la empresa; las más desarrolladas trabajan con mejores máquinas y más avanzadas tecnológicamente. De todas maneras, son actividades que se pueden llevar a cabo con máquinas que no son muy costosas y por ello se han difundido ampliamente y con muy bajas inversiones de capital.

Acopio y comercialización: No en todos los casos el producto es acabado dentro de la carpintería, en las más pequeñas aparece la figura del acopiador que compra productos sin acabar, los termina y los vende fuera de la provincia o a los dueños de locales de venta dentro del ámbito provincial. También hay acopiadores extraprovinciales que agregan valor al producto y lo venden a mejor precio. Pocas empresas diseñan sus productos y la gran mayoría los produce de acuerdo a los pedidos que recibe. Las más importantes poseen catálogos de presentación. A su vez, las ventas 
se realizan mayoritariamente en el mercado interno ya que por problemas de calidad y regularidad productiva no pueden venderse al exterior. La calidad, no es la óptima porque no se trabaja con madera seca, en la mayor parte de los casos.

Si atendemos al estímulo de esta actividad para el desarrollo local hay que mantener una continuidad en el tiempo en cuanto a disponibilidad de materia prima ya sea algarrobo u otras maderas que puedan ser utilizadas para mantener los puestos de trabajo.

\subsection{Problemas y dificultades detectados a partir del relato de los actores involucrados en la actividad}

a) Obtención de la materia prima, características de los sistemas de explotación forestal. La actividad forestal en el Chaco está basada en la explotación irracional del bosque nativo. Esta riqueza natural ha sido destruida en forma constante. Las áreas forestales más reforestadas no alcanzan apenas a compensar las áreas devastadas por la explotación forestal. La tabla que figura a continuación muestra el crecimiento de la frontera agropecuaria de la provincia en los últimos 15 años y evidencia claramente que se ha dado una gran expansión de las hectáreas sembradas con diferentes cultivos. Estas han pasado de 697.000 hectáreas en 1993 a 1.492 .000 hectáreas en 2008, e expensas, en gran parte, por la tala de monte nativo, sobre todo en el sudoeste de la provincia.

Hectáreas sembradas en la Provincia de Chaco, por cultivos y totales

\begin{tabular}{|c|c|c|c|c|c|c|c|c|c|c|}
\hline & 1993 & 1996 & 1999 & 2001 & 2002 & 2003 & 2005 & 2006 & 2007 & 2008 \\
\hline Trigo & 17.000 & 25.000 & 25.000 & 70.000 & 65.000 & 65.000 & 35.118 & 40.235 & 40.000 & 9120 \\
\hline Sorgo & 44.300 & 26.500 & 25.000 & 30.000 & 35.000 & 35.000 & 28.000 & 33.500 & 67.450 & 84.620 \\
\hline Arroz & 1.500 & 4.200 & 7.000 & 5.000 & 4.500 & 3.000 & 3.500 & 3.500 & 4.300 & 4.300 \\
\hline Tabaco & 444 & 556 & 780 & 944 & 1.000 & 1.489 & 600 & 1.062 & 1.100 & 1.100 \\
\hline maíz & 44.400 & 62.815 & 90.000 & 120.000 & 90.000 & 100.000 & 87.000 & 59.900 & 87.000 & 125.000 \\
\hline Girasol & 95.900 & 47.235 & 105.000 & 180.000 & 180.000 & 280.000 & 253.000 & 306.650 & 387.000 & 317.850 \\
\hline Algodón & 438.000 & 498.000 & 712.000 & 198.000 & 272.000 & 93.000 & 160.000 & 252.500 & 210.526 & 265.640 \\
\hline Soja & 55.300 & 72.085 & 200.000 & 380.000 & 550.000 & 600.000 & 586.000 & 468.500 & 573.700 & 684.000 \\
\hline $\begin{array}{l}\text { total } \\
\text { hectáreas } \\
\text { sembradas }\end{array}$ & 696.844 & 736.391 & 1.164 .780 & 983.944 & 1.197 .500 & 1.177 .489 & 1.153 .218 & 1.165 .847 & 1.371 .076 & 1.491 .630 \\
\hline $\begin{array}{l}\text { relación } \\
\text { resto menos } \\
\text { maíz y } \\
\text { sorgo/total }\end{array}$ & 0,8727 & 0,8787 & 0,901269 & 0,84755 & 0,895616 & 0,885349 & 0,900279 & 0,919887 & 0,887351 & 0,8594692 \\
\hline
\end{tabular}

Fuente. Elaboración propia sobre datos del PGB. 
Este uso irracional del recurso, producto del crecimiento de la actividad industrial y de los incentivos a la explotación agrícola, ha desencadenado en que se exploten montes cada vez más alejados y con menor calidad de las maderas que se encuentran en las zonas de talas. En los montes explotables, los mejores árboles ya han sido extraídos y quedan ejemplares de menores diámetros o especies enfermas, lo cual desde el punto de vista económico significa mayores costos de producción. La desmesurada explotación forestal con su consecuente deforestación, que abarca enormes superficies del Chaco ha provocado intensos procesos de erosión y como es lógico una irreversible degradación de los suelos, disfunciones ambientales irreversibles.

Los datos del inventario forestal ${ }^{5}$ revelan el efecto ocasionado sobre los algarrobales, tan característicos de la masa forestal chaqueña, en los años 70, algunas de las conclusiones se transcriben a continuación, pero por razones de extensión del trabajo, solo presentamos las que consideramos más representativas del problema que se generó.

a) El inventario forestal de la Provincia de Chaco del año 2005 muestra una muy baja presencia de algarrobo dentro de la masa boscosa; un 13,3\% en el caso del algarrobo negro y un $11.7 \%$ en el caso del algarrobo blanco.

b) En cuanto a la regeneración del árbol no se detectaron ejemplares de menos de $50 \mathrm{~cm}$, en la mayor parte de las unidades de muestreo, algunos árboles adultos pero no regeneración. Por cada 14 árboles adultos detectados solo hay 2 de regeneración y todos mayores a $50 \mathrm{~cm}$. De los fustes se puede mencionar que el $40 \%$ en el caso del algarrobo blanco y el $45 \%$ del algarrobo negro es industrializable, lo cual representa un porcentaje bajo, a su vez de esos porcentajes, la mayor parte es parcialmente industrializable y sólo una pequeña porción está sano y totalmente industrializable.

c) El diámetro promedio de estas especies es inferior a $30 \mathrm{~cm}$ (diámetro de corta recomendado): 24 para el algarrobo blanco y 21 para el negro. (Alfonso, Torrente y Carrió 2010)

Si bien existen exigencias en cuanto al diámetro mínimo de corte de la madera, en torno a los $35 \mathrm{~cm}$ de diámetro, en la actualidad esto no es un impedimento real para talar árboles de menor talla. A este hecho se suma la instalación, cerca de los montes explotables, de aserraderos de fábricas de otras provincias que sacan del Chaco la madera aserrada y le agregan valor fuera de la provincia. Esto sucede porque el cumplimiento efectivo de las leyes y planes de aplicación está condicionado a las posibilidades concretas de control y sanción por parte de los organismos pertinentes, los cuales están en íntima relación con su perfil productivo, se trata de una provincia que antepone el desarrollo y expansión agropecuaria a la forestal.

Por estas razones se vislumbra como objetivo proteger al bosque, separándolo de otras actividades productivas primarias. Tampoco se observa un resguardo activo de

${ }^{5}$ Fuente: Ministerio de la Producción de Chaco - Inventario Forestal - Elaboración: Ing. Enrique Wabö 
la riqueza forestal ni tareas para combatir las enfermedades del algarrobo, ni vigilancia de reproducción.

Los controles se realizan mediante el otorgamiento de guías para extraer una determinada cantidad de madera y luego certificar la extracción. El control lo ejecuta un guardabosques pero no siempre se efectiviza. Los sistemas de guías y permisos utilizados no son suficientes para frenar este proceso destructivo del algarrobo ni de otras especies valiosas, como el quebracho, especie que es explotada en forma indiscriminada e irracional y en muchos casos se practican acciones de contrabando que estimulan la degradación de una especie muy cotizada en el extranjero.

De las entrevistas hemos podido ver que el monte es visualizado como un obstáculo al desarrollo de la zona. En ocasiones el propietario de la tierra entrega en concesión su predio para que el obrajero limpie el terreno y usufructúe los beneficios de su explotación. Este sistema evidencia el mal manejo del monte, lo coloca en riesgo de extinción y genera secuelas ambientales y sociales. Nos parece importante resaltar que el valor del monte debe expresarse no sólo en lo ambiental sino como una actividad económica de la región ya que es sustento de muchas familias, además, como valioso motor para el desarrollo local.

La provincia del Chaco es potencialmente forestal pero existe un contrasentido representado por el hecho de que la mayor parte de las tierras que se podrían destinar a la explotación forestal y a la silvicultura son aptas para la agricultura la cual en el corto y mediano plazo produce beneficios que con la actividad forestal se producirían en el largo plazo. Esto último constituye un factor de bloqueo para la posibilidad de desarrollar cualquier tipo de iniciativa privada tendiente a ese tipo de actividades. Es por ello también que el productor forestal actúa como minero explotando indiscriminadamente el bosque nativo sin reponer siquiera el recurso extraído.

El grado de aprovechamiento del algarrobo es de aproximadamente del $20 \%$, es decir de una tonelada solo se aprovechan 200 kilos. Aunque de las entrevistas realizadas a los carpinteros de la zona se desprende que en la mayoría de los casos el grado de aprovechamiento actual está en torno al 16\% y 18\%. Los restos se regalan o venden a escaso valor y/o se utilizan como leña o aserrín. Sin embargo, existen muchos productos que se pueden llegar a obtener con la madera desaprovechada, pero la realidad indica lo contrario. No se realizan, en general, por dos tipos de factores: problemas de comercialización y falta de tecnología.

Algunas cuestiones ligadas a la necesidad de implementar una política forestal son:

a) La falta de una política adecuada que implica que no se utilicen todas las maderas que ofrece el monte, la extracción casi exclusiva del algarrobo hace que el recurso se esté agotando porque en lo referente al diámetro cortable autorizado no se respeta. Sin un adecuado manejo forestal del turno de corte del algarrobo (periodo desde que la planta nace hasta que tiene un diámetro de aproximadamente $30 \mathrm{~cm}$ ), está en el orden de los 60 años como mínimo. 
Haciendo un manejo forestal adecuado, trabajando con viveros forestales, preparando la plantación y cuidando el crecimiento, el turno de corte se puede acortar entre un $40 \%$ y un $50 \%$, en 30 o 40 años esta especie sería aprovechable.

b) También existe dificultad para que el sector privado invierta con un horizonte de 30 a 40 años ya que con la propiedad del bosque existe un problema. Es frecuente que el industrial maderero no sea el dueño de la tierra donde se encuentra el bosque, y el que es dueño de la misma no le da mayor importancia al recurso, "solo es propietario de una masa boscosa que ya estaba ahí, que no le ha costado nada". El productor no piensa en forestar para después vender la producción al industrial maderero y el industrial, al no ser titular de la tierra piensa que no puede encarar inversiones en una tierra que no es de su propiedad. El dueño del campo no ve todavía el negocio maderero y hasta tanto esta mentalidad no cambie la situación seguirá de la misma manera.

c) El principal inconveniente que causan los cambios operados en los últimos años con relación al abastecimiento del algarrobo es la calidad de la materia prima y el encarecimiento del recurso.

Esta realidad es conocida por los productores industriales que conforman el polo productivo que concentra carpinterías y aserraderos, pero ningún industrial entrevistado evidencia compromiso por la solución del problema; según se puede observar por sus comentarios: no existe. La concepción predominante es aprovechar el monte mientras se pueda y luego cambiar de actividad. Su solución a corto plazo la constituyen los secaderos que de alguna manera les permitiría seguir explotándolo sin necesidad de manejarlo o reforestarlo con la incorporación de nuevas especies.

Nos parece importante rescatar que, dada la creciente escasez de algarrobo, se hace indispensable ponerle una "patente" para que permita que se venda por su verdadero valor y de esa manera dedicar esta madera a los mercados en los que se estaría dispuesto a pagar lo que realmente vale.

La cantidad de microempresas es importante, son más de 700. Mientras se mantenga esta situación no se podrán lograr cambios positivos para un desarrollo local efectivo. La reforestación es la base para seguir produciendo al igual que la necesidad de implementar controles en el momento de la corta no cuando la madera ya está cortada. No hicimos una lectura completa acerca de la legislación, pero somos conscientes de que es probable que el problema no sean las leyes sino su efectivo cumplimiento.

Suponiendo que se comenzara a reforestar a tasas superiores a las actuales con controles adecuados, lo que si sería necesario para complementar esta medida es la capacitación del pequeño industrial porque es quien está produciendo y debe tener clara la importancia de no regalar su producto, así como también a sus empleados, establecer cupos de toneladas para cortar y generar esquemas que permitan el aprovechamiento integral de la madera.

La solución parcial o total de todos estos problemas podrían coadyuvar a un desarrollo local efectivo. 
b) Informalidad, carga impositiva e intermediación en la comercialización. Según los entrevistados el peso de los impuestos sobre la mano de obra es excesivo para el empleador. Esto hace que los trabajadores no se blanqueen lo que genera competencia desleal porque quien no paga los impuestos produce a menores costos y redunda en que pueda vender a menores precios, quitándole competitividad a quien está operando de acuerdo a la legislación vigente. Los que están en negro venden a acopiadores para que el producto salga fuera de la provincia, estos acopiadores venden fuera de la misma a precios más bajos de los que los que están en blanco generando una competencia desleal.

Los organismos de control cuando realizan inspecciones, por lo general, entrevistan a los que están inscriptos, faltaría un operativo de barrido territorial para verificar quienes no están inscriptos. Tener un empleado les resulta demasiado costoso, probablemente si a los impuestos lo pagasen todos la situación podría ser diferente, pero reconocen que hay "empresas" que no tienen posibilidad de subsistir si legalizan su actividad. Según carpinteros entrevistados, es probable que los micro emprendimientos que no están formalizados, no funcionen a largo plazo porque cuando deban regularizar el tema impositivo no podrían continuar con su actividad. Quienes están en blanco para el sistema, tienen plena conciencia de que un empleado en negro es un riesgo, pero en ocasiones lo asumen debido a los costos que implica incorporarlos al sistema formal. Por ello, tal vez gran parte de los emprendimientos agrupan a una parte importante de los hombres de una familia. La falta de cumplimento con los requisitos de formalidad, o el verdadero blanqueamiento de su dimensión de producción, por otra parte les impide acceder a cualquier crédito del sistema financiero o ayuda del Estado.

c) Asociativismo- En la mayor parte de los casos resulta muy difícil lograr que tiendan a asociarse aún en el caso de los productores medianos ya que no muestran predisposición a la asociación para la realización conjunta de actividades de producción. Esto limita la posibilidad de aplicar políticas asociativas ya que resulta difícil lograr acuerdos entre los actores productivos de este sector, los cuales se manifiestan incrédulos y no tienen una visión de trabajo conjunto.

En este contexto los acopiadores son los que crecen con menores riesgos y esfuerzo porque suplen el rol asociativo que debería darse entre productores para poder generar volumen y continuidad, como el productor no se une, no produce volumen y quien lo hace es el que acopia entre todos los pequeños quedando con las mayores ganancias por el solo hecho de la intermediación.

d) Falta de un lay-out eficiente y de seguridad en las plantas: Trabajan en condiciones insalubres por el polvillo y la falta de medidas de seguridad. Resulta muy difícil cambiar esta modalidad de trabajo. En general, salvo algunas excepciones, no tienen una distribución del proceso productivo planeada de manera tal que se ahorren recursos y esfuerzos. 
e) Falta de secaderos y tecnologías avanzadas de producción: Aunque ha crecido la instalación de hornos de secado, una parte importante no utiliza secadero artificial sino que, a lo sumo, llevan a cabo una técnica de presecado o secado natural, en aproximadamente 30 días, porque como solo trabajan para el mercado local aún no es un requerimiento que deban cumplir. Esto se ve permitido por la nobleza de la madera la cual, aunque se trabaje húmeda, no se dobla, ni se raja, lo que sumado a la falta de exigencias por parte del cliente, no hace necesario incorporar esta técnica. Pero la razón fundamental por la que no se la incorpora al proceso productivo es el tema de los costos adicionales que hay que afrontar para utilizarla. Adicionalmente al problema de costos se plantea el problema de que los secaderos que hay no dan a vasto para satisfacer a toda la demanda. Si se decide utilizar este servicio el productor debe esperar su turno y secar una cantidad de madera que permita completar la capacidad de las cámaras de secado. Las cámaras son muy grandes y se hace muy complicado llenarlas, por otra parte, se hace necesario colmarlas con un determinado espesor de madera, no se puede mezclar diferentes espesores y, es muy complicado obtener turnos. Todas estas son restricciones que impiden la utilización del sistema.

La ventaja de utilizar el secadero es la incorporación de especies distintas al algarrobo. El no utilizarlos, por otra parte, impide la incorporación y aprovechamiento de maderas alternativas al algarrobo para lograr una mejora en la calidad de los productos que se fabrican con el mismo, por ejemplo permite trabajar maderas blandas, pero estas sin un secado adecuado tienen un valor de comercialización más bajo que el algarrobo.

\section{f) Falta de capacitación del factor trabajo y de aplicación y conocimiento de técnicas} de gestión. Esto se evidencia en los diferentes tamaños de explotación, en las malas prácticas de producción, (falta de aprovechamiento integral de la madera, deficiente lay out y seguridad en las plantas, entre otras) y en la estimación de costos de producción para la fijación de precios de mercado. Muchos productores no tienen una idea clara de lo que realmente cuesta elaborar un producto, existe incluso, la posibilidad de que estén elaborando con pérdidas algunos de los artículos que fabrican y no lo perciban porque compensan esa pérdida con ganancias de otros productos elaborados. Esto último es un claro indicio de la falta de conocimientos y aplicación de las herramientas básicas de gestión utilizadas en la actualidad, no se llevan a cabo estimaciones de capital de trabajo óptimo, ni estudios de tasa de contribución marginal por producto a las utilidades de la empresa, tampoco aplican tableros de comando, ni se definen variables claves a controlar para asegurar determinados resultados.

A estos problemas se adicionan: Falta de financiamiento a tasas accesibles para el sector, dificultades de organización interna, altos costos, problemas de suministro de servicio, escaso grado de formalización jurídica y falta de certificaciones de calidad.

\section{Efectos ambientales}

Toda acción antrópica sobre el medio ambiente natural no intervenido provoca una serie de impactos que no siempre pueden ser mensurados. Estas acciones 
indiscriminadas alcanzan niveles de sobreuso o subuso de los recursos naturales localizados en un determinado espacio como es el caso de la explotación del algarrobo y su transformación en la provincia del Chaco.

También resulta imprescindible fijar estrategias de cara a una evaluación ambiental, vale decir contabilizar los efectos sociales, económicos y sanitarios provocados en la población, incluida en el primer objetivo de cualquier análisis ambiental y que en este caso está dedicada a las actividades que planteamos en el presente artículo, además de los problemas físicos que degradan el ambiente a diferentes escalas. Y no sólo en el espacio analizado ya que debemos tener en cuenta que el mismo está imbricado con otros interrelacionados con diferentes grados de afección. Nos estamos refiriendo a las provincias limítrofes de Formosa, Salta y Santiago del Estero, que conjuntamente con la del Chaco son las más afectadas por la deforestación con distintos propósitos. Todas ellas, a nivel nacional, deforestan más del $66 \%$ anual.

Como expresa María di Pace (1992), en Argentina existe un estilo de desarrollo con características favorables y desfavorables y que pueden ser tenidos en cuenta para nuestro caso. Entre estas últimas menciona: e) la valorización del suelo y la subvalorización del resto de los recursos naturales, "todo lo que se encuentra sobre la superficie es un obstáculo que deber ser arrasado (bosque, fauna) para poder utilizar el suelo con fines agropecuarios o urbanos", b) La valorización del recurso unido al desinterés por su conservación, muy en relación al tema de los bosques chaqueños y la utilización de algunas de sus especies como el algarrobo, c) el enmascaramiento de los problemas ambientales.

Argentina en general y el Chaco en particular poseen una escasa o nula conciencia ambiental. En los últimos años se percibe un tenue avance. En octubre de 2010 el Gobierno de la provincia del Chaco y la Dirección de Parques Nacionales firmaron un convenio marco para la implementación de Áreas Naturales Protegidas. El acta prevé la preservación de áreas naturales en los Departamentos del Impenetrable: Güemes y Almirante Brown. Por el convenio cada una de las partes se comprometen a crear un sistema de áreas protegidas o áreas donde haya que tomar medidas especiales para conservar la biodiversidad, promover la protección del ecosistema y de hábitats naturales, rehabilitar y restaurar ecosistemas degradados, proporcionar el mantenimiento de especies en entornos naturales; resguardar los valiosos componentes del patrimonio natural y cultural chaqueño; y desarrollar proyectos de uso sostenible de la tierra y aprovechamiento de los recursos naturales, compatibles con los objetivos de conservación. Además se constituirá un comité mixto integrado por dos representantes de la provincia y dos de Nación (Diario Norte, 03/10/2010). La plausible idea firmada por Chaco y la Dirección Nacional de Bosques es esperada con ansiedad y optimismo por los ambientalistas quienes esperan su pronta puesta en práctica. ${ }^{6}$

\footnotetext{
${ }^{6}$ Ante la demora en la sanción de la ley sobre Ordenamiento territorial de los bosques nativos por parte de la Legislatura chaqueña, el Poder Ejecutivo se vio obligado e dictar varios decretos como el 1671 que desalientan la tala de bosques nativos y el uso inapropiado de los recursos naturales. Declarando obligatoria la solicitud del certificado de conservación del monte nativo de todo inmueble rural ubicado
} 
La Red Agroforestal Chaco Argentina (REDAF) publicó en 2008 “A un año de la Ley de Bosques: panorama de la región chaqueña argentina" que describe la situación de las provincias de Chaco, Formosa, Santiago del Estero, Salta, Santa Fe y Córdoba, donde se asegura que el desmonte continúa sin ningún tipo de intervención estatal y se han deforestado más de dos millones de hectáreas desde la promulgación de la Ley Forestal. Desde principios de 2010 hasta el mes de octubre en el Chaco se habían talado aproximadamente 7000 has en forma ilegal. La norma obliga a las provincias a definir zonas de conservación y regular en ellas la actividad forestal, agrícola y ganadera con el fin de evitar la degradación del ambiente. Se fijaba en principio una moratoria total a la tala indiscriminada y los desmontes por un año hasta que se demarquen áreas de protección y se tomen medidas concretas para garantizar su sostenibilidad. Con todo muchos legisladores de las provincias con alto potencial forestal se opusieron porque ponían en peligro sus economías.

Ya se trate de una deforestación con fines industriales, como es el caso del algarrobo, o para la extensión de las fronteras agropecuarias, el hecho más remarcable es la destrucción de especies de difícil reproducción y que redundan en una pérdida irreparable del recurso y que atenta al desarrollo local sustentable y sostenible y, que en definitiva está signada por la aparición/desaparición de ciclos económicos a corto plazo y a veces irremplazables por otros que atiendan a la creación de fuentes de trabajo para frenar el grado de pobreza en que se hallan regiones marginales como la del nordeste argentino.

La demanda internacional de algunos productos forestales por sus precios asequibles, y por lo tanto tentadores está destruyendo riquezas naturales que ponen en peligro el futuro de nuevas generaciones y creando graves desequilibrios a nivel local, regional, nacional e incluso internacional. Máxime cuando estamos haciendo alusión a especies forestales de difícil y lenta recuperación existentes en espacios sumamente vulnerables. Algunas de las consecuencias de esta desproporcionada reacción negativa del medio ante el irracional uso de sus recursos ya se han expuesto en este trabajo tales como erosión, pérdida de suelos, a lo que se puede agregar la destrucción del hábitat de especies animales y vegetales, algunos en peligro de extinción, aparición de especies invasoras, entre otras.

Pero lo más complejo es la falta de observancia por todas las partes de las normativas nacionales y/o provinciales existentes lo que exacerba al máximo el desequilibrio ambiental, creando un conflicto de largo alcance. La falta de sensibilidad ambientalista por parte de productores crea un estado de anomia que trasciende todo acto que no va más allá de una acción puramente crematística. Los actores sociales, políticos y económicos hacen caso omiso a cualquier tipo de emprendimiento en ciernes o en activo con una mentalidad obtusa y e veces amparados por funcionarios

en la provincia, con el fin de lograr la protección ambiental para la protección ambiental, para la restauración, conservación y manejo sostenible de los bosques que deberá ser extendido por la Dirección Provincial de Bosques de la provincia del Chaco. 
oportunistas. Una mentalidad destructiva que siempre acompañó a los responsables de cualquier actividad económica en el territorio argentino.

Por otra parte, la deforestación está perjudicando los elementos básicos del ambiente: aire, agua y suelo llevando a estados de peligrosa y profunda crisis ambiental para la cual nuestros dirigentes no están preparados para actuar, menos aun para reparar.

La degradación ambiental a su vez, no sólo afecta al recurso forestal y su entorno, sino también a las personas relacionadas con la actividad de la tala y de la industria maderera. Destacan los efectos nocivos sobre los trabajadores forestales o industriales sin ningún tipo de apoyo previsional, incumpliendo las reglamentaciones vigentes acerca de las horas diarias laborables durante las cuales deben ejercer su trabajo y de reciente promulgación, ni obteniendo remuneraciones justas también fijadas por el Gobierno Nacional. Los operarios de aserraderos y carpinterías trabajan en ambientes totalmente insalubres y peligrosos proclives a contraer distintos tipos de enfermedades en los aparatos respiratorio y visual, y sin ningún tipo de precaución ante posibles accidentes laborales, todo en medio de establecimientos que no guardan las mínimas condiciones exigidas por la OMS. Lo más grave aún: trabajan para subsistir, pero sus ingresos son magros y no tienen estabilidad laboral, la mayoría de ellos informales.

Estas acciones tienen un punto de partida sin posibilidades de retorno a un ambiente similar o en tratativas de mejorarlo. La ausencia de una mentalidad preservasionista es consecuencia de las crisis coyunturales y estructurales donde todo vale. El problema se agrava porque en nuestro medio se practica una economía altamente especializada que no puede reaccionar ante cambios nacionales o internacionales y que los actores locales son incapaces de diversificarla para prevenir estos eventos. Es un mal enquistado en nuestra región.

El despilfarro del recurso, del que solo se utiliza lo más rentable, frena la capacidad para elaborar subproductos del algarrobo con colocación en el mercado local o regional. Estamos en presencia del subuso/sobreuso que se realiza del mismo poniendo en peligro su subsistencia como ya ocurriera con el quebracho y otras especies arbóreas de la región chaqueña. Decíamos que "las leyes no son el problema sino su incumplimiento" y hasta tanto esto no se revierta se seguirá con el despilfarro y su consecuente deterioro ambiental.

Otra carencia que atenta al uso racional de los recursos forestales es la falta de un inventario de los mismos por lo que no sabemos con lo que contamos para efectuar un plan de uso forestal efectivo, racional y tendiente a la preservación.

Teniendo en cuenta que hemos tratado del uso de un recurso vulnerable, que su reforestación es nimia y que el tiempo de desarrollo biológico tarda aproximadamente 60 años, su agotamiento supone el desplazamiento de gran cantidad de personas que trabajan en el obraje o en las carpinterías al alterarse continuamente la demanda de mano de obra obligándolos a emigrar a centros urbanos donde viven en míseras condiciones. Este éxodo significa exclusión social y económica a la vez que se ven obligados a ser partícipes de una segregación espacial pasando a engrosar el ya elevado número de 
personas que viven en similares condiciones y que a su vez fueron expulsados por el declive de otras actividades económicas por diferentes razones. Todo como se anotó por la falta de diversificación económica.

En definitiva, Argentina, no es un país forestal teniendo en cuenta la reducida superficie que abarca la masa forestal en comparación con otros países. Esto no significa que se deban manejar sus bosques nativos en forma inadecuada. Se deben trazar estrategias de recuperación, rehabilitación y enriquecimiento, sobre todo para aquellos degradados, aplicando políticas de créditos y subsidios para el manejo sustentable y atendiendo a prácticas de desarrollo local, como la que venimos de expresar en referencia e las áreas protegidas en ciernes del Chaco y todo lo que ello implica para las poblaciones nativas que habitan en ellos.

\section{Conclusiones}

Establecimos dos tipos de conclusiones: 1) las relacionadas con la dinámica productiva de estas actividades y 2) las relacionadas con el problema forestal.

1) Con relación a las actividades productivas asociadas con la madera, actualmente se plantea la imperiosa necesidad de replantear el esquema productivo para que cada micro, pequeño y mediano productor pueda insertarse competitivamente al sistema, esto implica un proceso de aprendizaje en el que deben participar activamente tres sectores de la sociedad: sector privado, sector público y sector educativo. Pero el sector analizado está subordinado a un conjunto de cuellos de botella y limitaciones que impiden su verdadero desarrollo.

Este conjunto de limitantes y características propias de la cadena foresto industrial provincial define un entorno de mucha precariedad en la explotación del recurso forestal como así también en la obtención de beneficios derivados del monte de gran parte de la población que vive y se mantiene gracias a estas actividades. Pero probablemente sea el resultado lógico de todo lo descrito con anterioridad.

Lo importante es destacar que no solo se pueden identificar debilidades para el sector. También existen fortalezas como por ejemplo las bondades del algarrobo y las posibilidades de lucrar con una madera que no abunda y que encuentra en la provincia un ámbito propicio para su desarrollo. Con la implementación de técnicas de manejo y enriquecimiento de monte nativo, así como con medidas apropiadas de reforestación que incluyan la posibilidad de que el productor pueda mantener el monte y a la vez obtener rentabilidad de esa tierra, tales como el desarrollo de modelos de explotación agro forestales y silvo pastoriles, en el mediano plazo se puede superar este problema y de esta manera fomentar el desarrollo local.

De acuerdo a lo ya expresado todavía hay factores que no se están desarrollando dentro de esta actividad tal como está operando en la actualidad: a) La posibilidad de incorporar otras maderas al proceso productivo, b) La posibilidad de incrementar 
las utilidades a través del mejoramiento del proceso productivo, c) La eliminación de productos que generan pérdidas y la fabricación de subproductos con valor agregado.

Si las empresas logran estabilizar su producción, asociarse y trabajar en el tema del diseño y elaboración de muebles de menor peso, lo que se lograría con el secado adecuado, y que permitan transportarse de manera tal que puedan ser ensamblados en su lugar de destino se abre la posibilidad de exportación y la posibilidad de incorporar nuevos mercados, esto es muy posible en el contexto cambiario actual de Argentina.

Otra fortaleza es el hecho de que la producción de muebles y aberturas de algarrobo está altamente concentrada en las provincias de Chaco y Formosa lo que permitiría orientar mejor la ayuda para el sector al igual que la formación del factor trabajo cualificado. Por otra parte, la ubicación estratégica de la provincia de Chaco con relación al MERCOSUR es una oportunidad inmodificable.

2) Con relación al problema forestal se puede concluir que el abastecimiento de algarrobo en las condiciones de explotación actuales no tiene un horizonte ni siquiera a mediano plazo, pero pueden incorporarse, con un cambio tecnológico y el desarrollo de secaderos, otras especies utilizables tanto para la producción de muebles como de otros productos, madera para la construcción, pisos, techos, aberturas, etc. Independientemente de que exista esta posibilidad es absolutamente indispensable desarrollar políticas de reconversión tecnológica y de reforestación apropiada a las necesidades de la provincia para preservar el algarrobo y poder aprovecharlo en toda su dimensión.

Mientras no se logre agregar valor al producto derivado del monte, este no será valorado, resulta por ello indispensable, en cualquier política de manejo del monte tener en cuenta este principio que es fundamental para comprender la dinámica que opera detrás de la explotación forestal.

"El ecosistema forestal del Gran Chaco, unidad fitogeográfica Sudamericana, está amenazado de extinción debido a la explotación irracional del monte nativo. Las masas forestales nativas sufren un constante deterioro debido a la ausencia de planes de manejo generados con base en información local, cuyo resultado final suele ser la tala indiscriminada de los bosques y su pérdida como recurso productivo. La explotación forestal se caracteriza por seleccionar sólo las especies valiosas, sanas y de buenas formas, transformando los montes en poblaciones con ejemplares enfermos y malformados, quedando sitios que son transformados en arbustales improductivos a los que se le suma la actividad ganadera de subsistencia, con una elevada presión de sobrepastoreo $\mathrm{y}$ pisoteo intensivo que deja los suelos desprotegidos $\mathrm{y}$ expuestos a la erosión del agua y vientos $\mathrm{y}$, con el avance de las fronteras agropecuarias se ha modificado profundamente 
la composición de las comunidades vegetales, sea eliminando las especies forestales más valiosas, destruyendo el estrato herbáceo y facilitando la invasión por especies arbustivas, o bien talando y quemando totalmente el bosque para crear campos destinados a la agricultura" (PIARFON- Chaco Subhúmedo, 2005).

La posibilidad en este sentido, en vistas a estimular un desarrollo local, está dada por el hecho de que existe una creciente presión en pos de la conservación de los bosques nativos e imposibilidad de muchos países de expandir sus bosques implantados en forma considerable por falta de espacio y baja tasa de crecimiento y el Chaco en este sentido no tiene esta restricción.

Finalmente, es importante destacar una receta que puede generar resultados exitosos: observar otras experiencias de emprendimientos para el desarrollo local que han logrado enfrentar los desafíos de la globalización aun sin ser de gran escala.

"La referencia a las "mejores prácticas" es especialmente importante para mostrar que los esfuerzos que se despliegan en escenarios locales (regiones, municipios, etc.) en América Latina y el Caribe, de forma aislada y, la mayoría de las veces, con la incomprensión o la falta de apoyos decididos desde las esferas centrales del Estado o la política oficial, no son ejercicios que deban abandonarse al logro de los siempre escasos y esporádicos recursos de la cooperación internacional o las iniciativas asistencialistas. Por el contrario, constituyen planteamientos necesarios de adaptación flexible, desde los diferentes territorios subnacionales, a las exigencias actuales de la fase de transición tecnológica y organizativa a la que asistimos y, en suma, a los requerimientos del ajuste estructural para el desarrollo en nuestras sociedades". (Alburquerque, 2001).

Esta afirmación de Alburquerque refuerza la idea de la importancia de que desde el Estado a través de sus diferentes estamentos es absolutamente indispensable que se tome en consideración la significación de estos emprendimientos y se asegure la continuidad de crecimiento de los mismos en el tiempo.

La industria maderera, en definitiva, puede estimular emprendimientos que estimulen el desarrollo local a diferentes escalas pero con la oportuna formación de los agentes locales, políticos y económicos, de la misma sociedad que formará parte del mismo y que podrá beneficiarse de los beneficios que reporte el mismo, favoreciendo un repertorio de iniciativas que abarque los postulados de este tipo de desarrollo. Amén de lo ya expresado con respecto e la conservación y continuidad en la provisión de la materia prima. 
Por otra parte, nos compromete como investigadores del área a revisar estas experiencias para establecer algunas líneas claras de acción para este sector y determinar las fases para elaborar un desarrollo local sostenible y sustentable.

\section{Referencias bibliográficas}

Alburquerque, Francisco \& Diputación de Barcelona. 1999. Manual del agente del desarrollo local. Colección de Manuales Ediciones SUR .1999. URL: http://www.docstoc.com/ docs/1499431/Manual-de-desarrollo-local

Alburquerque, Francisco et al. 2001. Desarrollo económico local y descentralización en América Latina: Análisis comparativo. Santiago de Chile, CEPAL/GTZ.

Alburquerque, Francisco. 1997. Desarrollo local y distribución del proceso técnico: Una respuesta e las exigencias del ajuste estructural. Santiago de Chile, CEPAL, 118 pp.

Alfonso, Elena, Daniela Torrente y Marcela Carrió. 2010. "La Responsabilidad Ambiental de las empresas madereras en el Chaco". II Congreso Internacional y IX Simposio de America Latina y el Caribe pp. 18 y ss.

Diario Norte. 2010. 30/09, 03/10. Resistencia, URL: http://www.diarionorte.com

Di Pace, María, (Coord.). 1992. Las utopías del medio ambiente. Desarrollo sustentable en la Argentina. Buenos Aires, Centro Editor de América Latina, IIED-AL, pp. 91-94.

Donato, Víctor. 2002. La Nueva Geografia Industrial Argentina. La Distribución Territorial y la Especialización Sectorial de las Pequeñas y Medianas Industrias en el año 2000. Buenos Aires, Observatorio Permanente de las PyMIs Argentinas.

Elizalde Hevia, Antonio. 2006. Desarrollo humano y ética para la sustentabilidad. Antioquia.

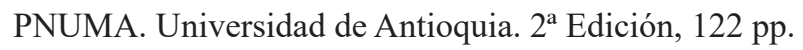

Elizalde Hevia, Antonio. 2003 Planificación estratégica y políticas públicas para el desarrollo local". Serie gestión Pública $\mathrm{N}^{\circ}$ 29. Santiago de Chile, Naciones Unidas. URL: http:// www.grupochorlavi.org/gobernanzaambiental/Documentos/planifterritorial.

URL: http://www.medioambienteonline.com/site/root/resources/analysis/1331.htm

Maeder, Ernesto. 1996. Historia del Chaco. Buenos Aires. Plus Ultra.

Miranda, Guido. 1980. Tres ciclos chaqueños (Crónica Historia Regional). Resistencia, Norte Argentino.

Mladinic Alonso, Hernán. 2002. Indicadores de desarrollo sustentable en la minería: El caso de Noranda. Disp. en http://www.medioambienteonline.com/web/guest/viewpointarticles/article/-/article/ug2M/21606/-1/1331.

Muscar Benasayag, Eduardo, Bruno Schmitt, Henrique (Eds., Coord.). 2008. Desarrollo local y medio ambiente en América Latina. Instrumentos y acciones. Madrid, Facultad Geografía e Historia, Departamento Análisis Geográfico Regional, UCM.

Muscar Benasayag, Eduardo, F. 2002. "Acerca de los problemas ambientales en los países del MERCOSUR. De la retórica e la práctica" en Dolores Brandis y Eduardo Muscar (coord.). MERCOSUR/Medioambiente. Algunos problemas/Algunas propuestas. Madrid, Facultad Geografía e Historia, Universidad Complutense de Madrid, pp. 7-23

Observatorio PyME regional Provincia de Chaco. 2005 Industria Manufacturera. EUDENE, Universidad Nacional del Nordeste. 2005. S/P 
ONU. 1987. Informe de la Comisión Mundial sobre el Medio Ambiente y Desarrollo (Comisión Brundtland): Nuestro futuro común. 11/12/1987. Nueva York

Proyecto de Investigación Aplicada a los Recursos Forestales Nativos (PIARFON). Proyecto: Bosques Nativos y Áreas Protegidas. UNNE-UNAF- Banco Mundial. 2003-2005.URL: http://medioambiente.gov.ar/?idarticulo $=948$

Redagroforestalargentina. 2008.

Rofman, Alejandro. 2000. Desarrollo regional y exclusión social. Transformaciones y crisis en la Argentina contemporánea. Buenos Aires, Amorrortu.

Ruz, Ana María y Mladinic Alonso, Hernán. 2005. Identificación de áreas de oportunidad en el sector ambiental de América Latina y el Caribe: casos exitosos de colaboración entre industrias para formular alianzas. Santiago de Chile. Serie Medio Ambiente y Desarrollo. No 93 CEPAL.

URL: www.ambiente.gov.ar/archivos/web/CAEFCPAN/20CHACO/REDAF/File/PDF/ONG 